
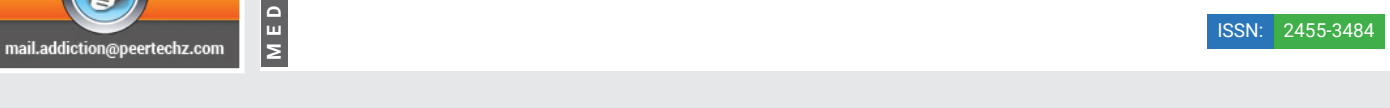

\title{
Trihexyphenidyl abuse in psychiatric outpatient clinic of a general hospital in Northern Nigeria
}

Received: 05 March, 2020

Accepted: 25 March, 2020

Published: 26 March, 2020

*Corresponding author: Raji Saheed Olanrewaju, Consultant Psychiatrist, Sarkin Maska Shehu Hospital (SMASH), Funtua Katsina State, Nigeria, E-mail: rajisaheed2003@gmail.com

Keywords: Trihexyphendyl; Anticholinergics; Abuse; Nigeria

https://www.peertechz.com

\section{Check for updates}

\author{
Raji Saheed Olanrewaju ${ }^{1 *}$ and Abba Mannir ${ }^{2}$ \\ ${ }^{1}$ Consultant Psychiatrist, Sarkin Maska Shehu Hospital (SMASH), Funtua, Katsina State, Nigeria \\ ${ }^{2}$ Post Intern Nurse ,Institution: Sarkin Maska Shehu Hospital (SMASH) Funtua, Katsina State, Nigeria
}

\begin{abstract}
Background: Concomitant prescription of anticholinergics with first generation antipsychotic medications is widely practiced in psychiatry to avert or abort extrapyramidal side effect resulting from the latter. Trihexyphenidyl (Benzhexol) is the most commonly prescribed and the most likely to be abused amidst the anticholinergics in Nigeria.
\end{abstract}

Objectives: To explore the prevalence and the associated factors for Trihexyphenidyl abuse among psychiatric outpatients in Nigeria.

Methodology: 64 stable outpatients who met the inclusion criteria were interviewed with a sociodemographic questionnaire and a ten items Drug Abuse Screening Test (DAST-10), other relevant data were obtained from their case notes at the psychiatric clinic of Sarkin Maska Shehu (SMASH) Hospital, Funtua, Katsina State. Data were tabulated and analysed with Microsoft Excel and version 11.65 of Window Program for Epidemiologist (WINPEPI).

Result: Mean age of participants was 36years, 33 (51.60\%) of the participants were males, 24 (37.50\%) were married while 36 (56.25\%) were employed. Schizophrenia $(38,59.40 \%)$ was the leading axis 1 diagnoses among the studied participants. 16 (25.\%) of the participants met the criteria for Trihexyphenidyl abuse.

Conclusion and Recommendations: Abuse potential of the Benzhexol and other anticholinergics calls for caution in its prescription amidst other disadvantages. Choice of atypical antipsychotics, gradual anticholinergic dose reduction, intermittent anticholinergic prescription and other ways were suggested to avert risk of abuse.

\section{Introduction}

The impact of several strict anti drug laws being promulgated in several parts of the world make the citizens to look elsewhere in seeking an alternative psychoactive substance to satisfy their urge. This has led to the rise in the number of identifiable psychoactive substances. Therapeutic drugs, food items, solvents, additives or other substances that are ordinarily not previously classified as psychoactive today may become one tomorrow upon recognition of their mind altering potentials. Prescription drugs and their derivatives are sometimes turned to by the substance abusers as a readily available substitute licit substance. This applies to the Over The Counter (OTC) as well as the Prescription Only Medications (POM).
According to studies conducted in various parts of Nigeria, Prescription Only Medications (POM) like codeine (and other opioid analgesics), sedatives (eg rohyphnol, diazepam), barbiturates (eg phenobarbitone, amylobarbitone), steroids, amphetamine type stimulants, trihexylphenidyl (THP, exol, benzhexol, artane) are next only to marijuana among the list of commonly misused substances [1-3]. Indiscriminate use of these drugs is known to be hazardous, as they are meant to be controlled and moderately consumed under the guidance of a licensed prescriber [2]. Among patients with neuropsychiatric disorders, some of the medications that are meant for therapeutic purposes may be converted or diverted for recreational purposes. This is a common phenomenom for methadone in opiod addiction substitution therapy setting and methylphenidate in the treatment of attention deficit hyperkinetic disorders usually in paediatric psychiatry units. 
In general adult psychiatry, anticholinergic medications are usually prescribed as an accompaniment of typical or the First Generation Antipsychotics (FGAs) to prevent or treat the commonly associated Extrapyramidal Symptoms (EPS). They are also commonly prescribed in Neurology clinic for treatment of Parkinsonian symptoms. Among the commonly available oral anticholinergic drugs, benztropine is the commonly prescribed agent in the United State (US), while Trihexyphenidyl (THP) is commonly prescribed in Nigeria. Parenteral biperidine is also readily prescribed in Nigeria for treatment of acute dystonic reaction which is a severe acute presentation of extrapyramidal symptom. Orphenadrine citrate is as well readily available in oral anticholinergic formulation in Nigeria but it is much more prescribed in treatment of spasmodic musculoskeletal symptoms in orthopedic and rheumatology clinics. It is rarely used by psychiatrist possibly because THP is a cheaper alternative in our resource poor setting. Other anticholiyclinergic agents like benztropine and procyclidine are not readily available in Nigeria. Several other medication that are classified as antihistamine (eg bropheniramine,, diphenhydramine, chlorpheniramine) antidepressants (especially the tricyclic antidepressants) antipsychotics (eg chlorpromazine) antiviral (eg amantadine) have inherent anticholinergic properties which can be explored in comorbid conditions or other situations, which will then nullify the need for further anticholinergic prescription [4].

\section{Study rationale}

Studies have established the abuse potential of all anticholinergic medications that are usually prescribed primarily for treatment of EPS in psychiatric settings. Most studies [5], recognized THP as the most potent and the most likely to be abused of all the commonly prescribed anticholinergics. None of such studies was conducted in Nigeria to enable recognition of the magnitude of the potential for THP abuse.

THP is known by some patients and citizens in the study setting for its tendency to cause euphoria. Menial labourers in Northern Nigeria has local parlance for THP ie " farin mallam" aside from the common brand names like benzhexol, exol, and artane. This implies the possible popularity and prevalence of THP abuse in the proposed study setting as well as in the community. Abuse of THP in hot weather of our typical tropical climate by athletes and menial labourers can result in fatal hyperthermia. Conducting such study in this setting will avert the repeat of a similar pattern of opioid prescription misuse (especially, codeine and tramadol) that is already in epidemic proportion in Nigeria [6].

\section{Abuse potential of trihexyphenydil}

THP purposively bind to muscarinic and dopaminergic receptors to reduce the extrapyramidal side effects. The affinity for the dopaminergic receptor at high dosage is possibly responsible for the neuropsychiatric effect like hallucination and euphoria with abuse potential upon stimulatimg central nervous system reward system, Oliver Sack (a neurologist) narrated his euphoric and hallucinatory experience upon taking an overdose of THP in 1960. Bolin reported first ever case of abuse concurrently in a young woman who increase her therapeutic dosage from $2 \mathrm{mg}$ daily to $30 \mathrm{mg}$ to attain euphoric state. This was followed by other case series in the 1960 s and 1970s [7].

THP abuse prevalence varies from $1.1 \%$ in the population to as high as 34\% [5] in Psychiatric setting in literatures, the wide disparity in prevalence data may be due to easy accessibility of the latter group to the medication.

\section{Other adverse effects of trihexyphenidyl (THP) and other anticholinergic medications}

Aside from its abuse potentials, indiscriminate anticholinergic use can worsens some pre-existing medical illnesses or precipitate some illnesses in the predisposed via its effects on the central and peripheral nervous system [8]. Delirium, Neuroleptic Malignant Syndrome (NMS), aggravation of tardive dyskinesia, worsening psychosis, memory impairment are some of the other negative effect effects it may has on the neuropsychological system.

Severe anhidrosis and fatal hyperthermia can result from anticholinergic drug use in people that engage in rigorous physical activity during hot weather . This is important in agrarian society (like Nigeria) with tropical climate like ours where peasant farmers, labourers and sometimes athletes indulge in recreational drug use for performance enhancement.

Blindness has been reported from precipitation of narrow/ closed angle glaucoma. Xerostomia (dry mouth) can occur with risk of dental caries, halithosis and suppurative parotitis Cardiovascular complications (eg arrhythmias) can also occur. Chronic constipation from long term use can result in paralytic ileus, hemorrhoids, anal fissures and anal fistula. Risk of urinary retention call for caution in its prescription in elderly male patients who may have underlining prostate disease.

Synergistic anticholinergism may result upon concomitant prescription with other medications that have significant anticholinergic/ atropine-like effects. Cannabinoids, opioids, barbiturates, and alcohol may exhibit additive effects with anticholinergic agents which call for caution in its prescription in polysubstance abusers $[9,10]$.

\section{Magnitude of anticholinergic drug use in mental health institutions}

Agboinle, et al. [11] reported the prevalence of adjunctive Trihexyphenydyl (THP) prescription of $82.6 \%$ along with antipsychotic medications $(81.2 \%$ of all psychotropic prescriptions), in a descriptive survey conducted at Psychiatric Hospital Benin-city, Nigeria. This is similar to the finding of Patte and Hema who found $92 \%$ prevalence of co-prescription of THP with risperidone in a retrospective twelve-months survey conducted in a psychiatric outpatient clinic in India spanning from July 2015-2016 [12]. A lower co-prescription rate of $22 \%$ was reported by Al-Ghamdy et al in a Saudi study conducted in 1996 [13]. 
This is a reflection of the commonality of adjunctive THP prescription practice among prescribers. To the best of author's knowledge, no Nigerian study had explored the extent of abuse of THP or other anticholinergics in Nigeria.

\section{Aims}

This study is intended to explore the prevalence of THP misuse and the associated factors amidst outpatients, attending psychiatric clinic of Sarkin Maska Shehu Hospital (SMASH), Funtua.

\section{Methodology}

This study was conducted in the psychiatry clinic of SMASH, Funtua. It is a secondary health care facility owned by Katsina State Government of Nigeria. The psychiatry unit of the hospital is run on all weekdays, attending to about 20-60 clients each day. Most patients that require inpatient care are referred to the state owned psychiatric hospital in the capital city of Katsina. Though fewer of such patients that are considered as low- moderate risk despite illness severity are sometimes admitted in the male, female, gynaecology, antenatal, postnatal and children ward of the hospital. Acute, short stay inpatient care and emergency room services are sometimes offered in the observation room of outpatient department clinic, accident and emergency unit to enable crisis resolution for the severely agitated patients.

Ethical approval to conduct the study was sought from Ethical Review Committee of the Katsina State Ministry of Health. Verbal informed informed consent was obtained from each participant before being recruited to partake in the study. Each participants was interviewsed with a sociodemographic questionnaire and a ten-item drug abuse screening test (DAST-10, APPENDIX)

\section{Study participants}

Consenting outpatient adult participants in the age range of 18- 65 years, who have been diagnosed of Severe Mental Illness (SMI) and had been taking trihexyphenidyl (THP, benzhexol, artane, exol) within the last 12 -months were considered to have met the inclusion criteria. The younger, elderly, nonconsenting and people with cognitive impairment were not recruited.

\section{Study instruments}

DAST-10 is brief screening instrument, that is useful in assessment of psychoactive substance abuse (other than alcohol and tobacco) in the past twelve months. It was adapted from the 28-item parent version (DAST-28) whose items parallel those of Michigan Alcoholism Screening Test (MAST). DAST10 has valid psychometric properties (sensitivity, specificity) [14] and has been used previously by other authors locally and internationally $[15,16]$.

The word "artane" or "exol- 5 " is substituted for "drug" in the original instrument, while the question /item number 3 was reworded. This is to enable better understanding and ease (reverse) scoring. A score of 1 is allotted for every 'yes' answer.
Cut-off score 3 was used to determine the pattern of use/ abuse as the score of 0-2 indicates no/low risk of drug abuse, 3-5 is indicative of abuse or harmful use of drug while score of 6 and above indicate addiction/ drug dependent. This is in line with the standard scoring criteria [14] for the instrument and has also been applied in previous studies [16].

Appropriate interventional services or referral for rehabilitation were offered for individuals who met abuse criteria.

\section{Data analysis}

Collected data were tabulated and displayed in tables, then analysed with 11.65 version of Window Program for Epidemiologists (WINPEPI-11.65), using appropriate statistical tests.

\section{Results}

Data of 64 out of 70 patients recruited for the stud $y$ were analysed, the remaining 6 were discarded due to noncompletion.

Mean age of participants was 36 years $(35.91 \pm 10.67)$. Majority $(33,51.60 \%)$ of recruited participants were males. Only $24(37.50 \%)$ of the participants were married, while the remaining were either single $(22,34.40 \%)$, divorced $(15,23.40 \%)$ or widowed $(3,4.70 \%)$. More than a half of the recruited participants $(36,56.25 \%)$ engage in various forms of occupations, 7 participants reported $(10.90 \%)$ being full time housewife, while 19 participants were jobless. (Table 1 About a quarter of the participants $(15,23.40 \%)$ reported various side effects on taking trihexyphenidyl. Blurring of vision is the commonest of the reported side effects of the medication. Less than a half $(30,46.70 \%)$ reported various withdrawal symptoms, rigidity is the leading withdrawal symptoms reported by participants. Only 6 participants reported use of psychoactive substances other than trihexyphenidyl. Schizophrenia was the leading axis I diagnosis amidst the participants, it was found in more than half of the participants $(38,59.40 \%)$ while only 4 particioants $(6.2 \%)$ were diagnosed of psychoactive substance use disorders.

Based on the standard scoring system for the Ten-items Drug Abuse Screening Test (DAST-10) questionaire, about a quarter of the participants $(17,16.60 \%)$ had low or no risk of abuse (score of zero), the pattern of use in about a half of the participants $(33,48.40 \%)$ was risky (scores of $1 \& 2$ ). A quarter of the participants $(16,25.00 \%)$ abuse THP ( harmful use and dependent) (Table 2) Only male gender \& use of other psychoactive substances have significant relationship with THP abuse $(\mathrm{p}<0.05)$ (Table 3$)$

\section{Discussion}

The prevalence of THP abuse was found to be $25 \%$ in this study. This was lesser than the prevalence of $34 \%$ reported by Naja \& Halaby in their comprehensive review on anticholinergic use and abuse [5]. Up to a third of attendees were also reported 
to be abusing various anticholinergics in other mental health settings [4]. Most THP abusers in this study were unmarried young men. Same was found in most other studies conducted in several parts of the world like Saudi Arabia and Brazil [17,18]. Amidst the sociodemographic factors, male gender is the only factor that has a significant relationship with THP abuse. This follows the general trend of other psychoactive substance use which is usually more prevalent in males than female gender [19]. The Brazilian and Saudi studies also stated that other sociodemographic variables like being unemployed is common amidst THP abusers, This contrast with this study as most of the THP abusers are employed in this study probably because most of the participants engages in primary activities (like farming , manual labour\} requiring physical exertion and the THP may then be used for performance enhancement.

Among clinical factors, people who reported no history of other substance use were overrepresented in the THP abusers category and this was found to be statistically significant. Most THP abusers in this study reported not using other psychoactive substances. This is contrary to the finding of other studies that describe THP abusers as polydrug users $[17,18]$. possibly because lower number of participants reported history of use of other substances in this study. Another possible explanation for the contrasting finding is the use of a standardized drug abuse screening questionnaire for appropriate designation of THP abuse. Such was not used in other studies. Participants

Table 1: Sociodemographic Features of the Participants.

\begin{tabular}{|c|c|c|}
\hline Variable & Frequency (64) & Percentage (100) \\
\hline \multicolumn{3}{|c|}{ Age $(x=35.91 \pm 10-67)$} \\
\hline$<$ mean age & 34 & 53.10 \\
\hline $\begin{array}{c}\geq \text { mean age } \\
\quad(\geq 36)\end{array}$ & 30 & 46.90 \\
\hline \multicolumn{3}{|l|}{ Gender } \\
\hline Female & 31 & 48.40 \\
\hline Male & 33 & 51.60 \\
\hline \multicolumn{3}{|l|}{ Marital status } \\
\hline Divorced & 15 & 23.40 \\
\hline Married & 24 & 37.50 \\
\hline Single & 22 & 34.40 \\
\hline Widowed & 3 & 4.70 \\
\hline \multicolumn{3}{|l|}{ Occupations } \\
\hline Automech & 2 & 3.1 \\
\hline Civil serv & 1 & 1.6 \\
\hline Driving & 2 & 3.1 \\
\hline Farming & 11 & 17.2 \\
\hline Housewife & 7 & 10.9 \\
\hline Lab Tech & 1 & 1.6 \\
\hline Labourer & 3 & 4.7 \\
\hline Retired & 2 & 3.1 \\
\hline Teaching & 2 & 3.1 \\
\hline Tiler & 1 & 1.6 \\
\hline Trading & 13 & 20.3 \\
\hline Jobless & 19 & 29.7 \\
\hline
\end{tabular}

Table 2: Clinical Features of the Participants.

\begin{tabular}{|c|c|c|}
\hline Variable & Frequency (64) & Percentage (100) \\
\hline \multicolumn{3}{|l|}{ Side Effects } \\
\hline None & 49 & 76.60 \\
\hline Blurred Vision & 9 & 7.80 \\
\hline Insomnia & 4 & 6.20 \\
\hline Dizziness & 2 & 3.10 \\
\hline Constipation & 1 & 1.60 \\
\hline Somnolence & 1 & 1.60 \\
\hline Xerostomia & 1 & 1.60 \\
\hline Euphoria & 1 & 1.60 \\
\hline \multicolumn{3}{|l|}{ Withdrawal Symptoms } \\
\hline None & 34 & 53.10 \\
\hline Rigidity & 9 & 14.10 \\
\hline Somnolence & 8 & 12.50 \\
\hline Sialotrrhea & 4 & 6.20 \\
\hline Tremor & 3 & 4.70 \\
\hline Bradykinesia & 3 & 4.70 \\
\hline insomnia & 2 & 3.10 \\
\hline Tremor, Rigidity & 1 & 1.60 \\
\hline \multicolumn{3}{|l|}{ Misuse of other substances } \\
\hline None & 58 & 90.60 \\
\hline $\begin{array}{l}\text { Tbc, Cnbs, } \\
\text { BZP }\end{array}$ & 2 & 3.10 \\
\hline Caffeine & 3 & 4.70 \\
\hline Tobacco,cann abis & 1 & 1.60 \\
\hline \multicolumn{3}{|l|}{ Primary Azis I Diagnosis } \\
\hline BAD & 12 & 18.8 \\
\hline Depression & 10 & 15.6 \\
\hline Schizophrenia & 38 & 59.4 \\
\hline SUD & 4 & 6.2 \\
\hline \multicolumn{3}{|l|}{ DAST SC ORE } \\
\hline $\begin{array}{l}\text { Abstinence/ } \\
\text { Low Risk (0) }\end{array}$ & 17 & 26.6 \\
\hline Risky (1-2) & 31 & 48.4 \\
\hline $\begin{array}{l}\text { Harmful use } \\
\qquad(3,4,5)\end{array}$ & 8 & 12.5 \\
\hline Dependent (6 and above) & 8 & 12.5 \\
\hline
\end{tabular}

with psychoactive use history have other means of attaining euphoria or enhancing performance, unlike the non substance users that may not be aware of the ways of attaining euphoria rather than through the prescribed drugs which they might have gotten through serendipity. In clinical settings non treatment adherent patients sometimes single out THP as the only preferred ones amidst other psychotropic medications (upon recognizing its euphoric potential) while being neglectful of others.

Schizophrenia is the commonest axis I diagnosis among THP abusers in this study but has no significant relationship with THP misuse as reported in other studies elsewhere [20]. 
Table 3: Relationship between THP Abuse Sociodemographic/Clinical Factors

\begin{tabular}{|c|c|c|c|c|c|c|c|}
\hline & \multirow[t]{2}{*}{ Variable } & \multicolumn{2}{|c|}{ DAST SCORES } & \multirow{2}{*}{$\begin{array}{l}\text { To } \\
\text { tal }\end{array}$} & \multirow[b]{2}{*}{ Chi sq } & \multirow{2}{*}{$\begin{array}{l}\text { d } \\
\text { f }\end{array}$} & \multirow[b]{2}{*}{$P=$ value } \\
\hline & & $\begin{array}{c}\text { NO HARMFUL } \\
\text { USE }\end{array}$ & $\begin{array}{l}\text { HARMFUL USE/ } \\
\text { DEPENDENT }\end{array}$ & & & & \\
\hline \multirow[t]{2}{*}{ Age } & $>36 y e a r s$ & 25 & 9 & 34 & 0.082 & 1 & 0.774 \\
\hline & $\geq 36 y e a r s$ & 23 & 7 & 30 & & & \\
\hline \multirow[t]{2}{*}{ Gender } & Female & 27 & 4 & 31 & 4.619 & 1 & 0.032 \\
\hline & Male & 21 & 12 & 33 & & & \\
\hline \multirow[t]{2}{*}{ Marital Status } & Married & 20 & 4 & 24 & 1.400 & 1 & 0.237 \\
\hline & Unmarried & 28 & 12 & 40 & & & \\
\hline \multirow[t]{3}{*}{ Occupational Status } & Employed & 23 & 13 & 36 & 5.550 & 2 & 0.062 \\
\hline & Retired & 2 & 0 & 2 & & & \\
\hline & Unemployed & 23 & 3 & 26 & & & \\
\hline \multirow[t]{2}{*}{ Use of Other Substances } & No & 46 & 12 & 58 & 6.034 & 1 & 0.014 \\
\hline & Yes & 2 & 4 & 6 & & & \\
\hline \multirow[t]{4}{*}{ Axis I Diagnosis } & BAD & 8 & 4 & 12 & 7.294 & 3 & 0.063 \\
\hline & Depressiom & 9 & 1 & 10 & & & \\
\hline & SUD & 1 & 3 & 4 & & & \\
\hline & Schizophre nia & 30 & 8 & 38 & & & \\
\hline
\end{tabular}

\section{Conclusion and recommendations}

A quarter (25\%) of participants in this study abuse THP. Male patients and those without history of psychoactive substance abuse are more likely to abuse THP in attendees of mental health clinic. Efforts should be geared towards preventing the surge in THP misuse in patients. It is recommended that proper attention be paid to this subgroup of individuals in prescription of anticholinergics.

Abuse potential of the THP and other anticholinergice calls for caution in its prescription amidst other disadvantages. Easy availability, affordability and indiscriminate prescription will give serendipitous patients sufficient time to realise the euphorigenic and addictive potentials of THP [20]. Anticholinergics should be tailed off after initial prescription of about 3-months to ease gradual cessation. Alternative anticholinergic medications with lesser addictive potentials like orphenadrine (norflex), biperidine (akinetone) and procyclidine should be considered when available. Worthy of note is that orphenadrine is readily available in Nigeria and may be a feasible (though costlier) alternative with lesser anticholinergic, euphorigenic or addictive effects [4]. Orphenadrine is noted to have a narrower therapeutic index and this cause for caution in its prescription in suicidal patients to avert risk of overdose toxicity [21], Other medications with intrinsic anticholinergic properties (like bropheniramine, chlorpheniramine, hyoscine) can be used. Amantadine (dopamine agonist) can be used control the EPS without incurring anticholinergic effect [4]. Co-prescription of other psychotropic medications with intrinsic anticholinergic features will reduce the need for THP eg chlorpromazine, amitriptylline, olanzapine, paroxetine). For patients on typical long acting antipsychotic (LAA, depot medications), the duration of anticholinergic coverage should not exceed two weeks as the EPS from LAA usually occur within the first week of injection and it is less likely after ten days of injection. Preference should be given to atypical antipsychotics as they have lesser risk of extrapyramidal effect, while still being mindful of the possible metabolic consequences before they could ensue. Arbitrary quantity of anticholinergic prescription (eg 10 doses per month) on pro re nata ( $\mathrm{p} \mathrm{n}$ ) basis may be given to abort EPS in patients [4]. Reducing dosage of FGA after clinical improvement and stability may suffice in eliminating the EPS, effacing the need for anticholinergic medication [22].

\section{References}

1. Moses A (2010) National Focal Point Drug Abuse and Drug Dependence Treatment Situation. Link: https://bit.ly/33MzSPC

2. NSRP (2017) How an improved understanding of drug use can contribute to peace and stability in Nigeria. 1-6. Link: https://bit.ly/2JcOdeV

3. Adamson TA (2015) Descriptive national survey of substance use in Nigeria. J Addict Res Ther 06. Link: https://bit.ly/3dumPXr

4. Koola MM (2018) Anticholinergics to treat antipsychotic-induced extrapyramidal symptoms: Time to avoid this practice. Asian J Psychiatr 100 101. Link: https://bit.ly/2QJ1Gi

5. Naja WJ, Halaby A (2017) Anticholinergic Use and Misuse in Psychiatry: A Comprehensive and Critical Review. J Alcohol Drug Depend 05: 5-8. Link: https://bit.ly/3bp0qsQ

6. Raji SO, Inogbo CF, Oriji S, James BO (2013) Seizures in a young adult Nigerian male abusing codeine containing cough syrup. Nigesria J Basic Clin Sci 10 98-99. Link: https://bit.ly/2UgYfSu

7. Marken PA, Stoner SC, Bunker MT (1996) Anticholinergic Drug Abuse and Misuse 5: 190-199. Link: https://bit.ly/2JfvA9Z

8. Buck ML (2011) Trihexyphenidyl for the Management of Dystonia in Children Pediatr Pharmacother 17: 1-4

9. Monroe S (2003) Center for Drug Evaluation and Research

10. Management MR (2018) Antiparkinson's Agents Therapeutic Class Review (TCR) FDAAPPROVED INDICATIONS. Link: https://bit.ly/2UkjSkJ

11. Agbonile IO, Famuyiwa O (2009) Psychotropic drug prescribing in a Nigerian psychiatric hospital. Int Psychiatry. 6: 96-98. Link: https://bit.ly/2QNLJrp

12. Usharani PH, Hema NG, Nagaraj AM (2018) Antipsychotics in schizophrenia : a retrospective study of drug utilization pattern in out $\mathrm{p}$ atient department of psychiatry at a tertiary care hospital. Int J Basic Clin Pharmacol 7: 167-172. Link: Link: https://bit.ly/2vTPioS

13. All-Ghamdy Y, N A-Q, Abdelghadir M, Al'Habeeb T, Ahmad S (1999) Psychotropic Drug Prescriptions in Al-Qassim Region, Saudi Arabia. Vol. 5, Eastern Mediterranean Health Journal 27-34. Link: https://bit.ly/39jOFm7 
14. Skinner HA (1982) The Drug Abuse Screening Test. Addict Behav 7: 363-371 Link: https://bit.ly/2JhyvPC

15. Adekeye OA, Odukoya JA, Chenube O, Igbokwe DO, Igbinoba A, et al. (2017) Subjective Experiences and Meaning Associated with Drug Use and Addiction in Nigeria: A Mixed Method Approach. Glob J Health Sci 9: 57. Link: https://bit.ly/3am2z8H

16. McCabe SE, Boyd CJ, Cranford JA, Morales M, Janie Slayden (2006) A modified version of the Drug Abuse Screening Test among undergraduate students. J Subst Abuse Treat 31: 297-303. Link: https://bit.ly/2y2L6ng

17. Qureshi NA (1992) Trihexyphenidyl (artane) abuse among Saudi psychiatric patients. Ann Saudi Med 12: 391-394. Link: https://bit.ly/33QHlgz

18. Nappo S, de Oliveiria L, Sanchez Z, Carlini Ede A (2005) Trihexyphenidyl (Artane)_a Brazilian study of its abuse. Subst Use Misuse 40: 473-482. Link: https://bit.ly/39jaMsV

19. World Health Organization (2010) Atlas of Substance Use Disorders: Resources for the Prevention and Treatment of Substance Use Disorders (SUD) 1: 1-4.

20. Qureshi NA, Alamri AH, Abdelgadir MH, El-Harka E (1996) Trihexyphenidyl abuse: A controlled investigation between users and misusers. Arab $\mathrm{J}$ Psychiatry 7: 139-151

21. Gjerden P, Bramness JG, Slørdal L (2008) The use and potential abuse of anticholinergic antiparkinson drugs in Norway: a pharmacoepidemiological study. Br J Clin Phaemacology 67: 228-233. Link: https://bit.ly/2UiRU8X

22. Sheikh W (2019) Prophylactic Use of Trihexyphenidyl (Artane) In Schizophrenia and Psychosis: A Critical Review of Literature to Guide for Evidence Based Practice in Zambia. Med J Zambia 46: 133-139. Link: https://bit.ly/33KxxVk

\section{Discover a bigger Impact and Visibility of your article publication with} Peertechz Publications

\section{Highlights}

* Signatory publisher of ORCID

* Signatory Publisher of DORA (San Francisco Declaration on Research Assessment)

* Articles archived in worlds' renowned service providers such as Portico, CNKI, AGRIS, TDNet, Base (Bielefeld University Library), CrossRef, Scilit, J-Gate etc.

* Journals indexed in ICMJE, SHERPA/ROMEO, Google Scholar etc.

* OAI-PMH (Open Archives Initiative Protocol for Metadata Harvesting)

* Dedicated Editorial Board for every journa

* Accurate and rapid peer-review process

* Increased citations of published articles through promotions

* Reduced timeline for article publication

Submit your articles and experience a new surge in publication services (https://www.peertechz.com/submission).

Peertechz journals wishes everlasting success in your every endeavours

Copyright: ( 2020 Olanrewaju RS, et al. This is an open-access article distributed under the terms of the Creative Commons Attribution License, which permits unrestricted use, distribution, and reproduction in any medium, provided the original author and source are credited.

Citation: Olanrewaju RS, Mannir A (2020) Trihexyphenidyl abuse in psychiatric outpatient clinic of a general hospital in Northern Nigeria. J Addict Med Ther Sci 6(1): 003-008. DOI: https://dx.doi.org/10.17352/2455-3484.000029 